\title{
EL PROBLEMA DE LA INTEGRACION EN LAS SOCIEDADES MODERNAS AVANZADAS
}

\author{
Juan Carlos Alútiz Colorado*
}

La cuestión de la integración social, como problematización del hecho constitutivo de la sociedad, ha supuesto una preocupación recurrente de los científicos sociales desde la misma génesis de sus disciplinas de investigación, llegando a representar dentro de la teoría sociológica uno, cuando no el principal, de sus capítulos de referencia. La pretensión con la que abordamos en este artículo la vieja inquietud de la integración social nace, precisamente, de la necesidad de revisar los fundamentos del «vínculo social» a la luz de la propia dinámica en que se nos presentan las estructuras organizativas e institucionales en la actualidad, de manera tal que, tras recorrer una breve trayectoria a «lomos de los clásicos», podamos aventurarnos en la empresa de ofrecer un diagnóstico de su estado en las llamadas sociedades modernas avanzadas.

\section{El diálogo con los clásicos}

El punto de partida de esta pequeña tournée touristique al corazón del discurso sociológico lo vamos a comenzar en Durkheim, y no porque sus precursores, tales como Comte, Spencer, etc., no tuvieran presente dicho referente integrativo en sus diseños de comprensión sociológica, sino porque es indiscutible que es con este autor y su escuela donde con mayor espacio y relevancia se va a tratar el tema en estudio, estableciendo las bases para su posterior debate.

Durkheim, en su particular lucha para investir a la incipiente sociología de un estatuto científico, cimentará su estrategia de investigación

\footnotetext{
* Universidad Pública de Navarra.
} 
en torno a la integración en la búsqueda de un indicador social en el que visualizar las diferentes formas de solidaridad social en las que ésta se articula a lo largo de la trayectoria histórica de las sociedades, encontrando en el «derecho», como explicitación de la normatividad social, dicha disposición objetual de referencia integrativa.

Con este «indicador» en la mano, Durkheim clasificará las diferentes modalidades en que se presenta para identificar las solidaridades sociales a las que corresponde, encontrando dos tipos esenciales de estipulaciones jurídicas: las represivas y las restitutivas. Las primeras serán asociadas a una solidaridad mecánica, llamada de este modo por basarse en las semejanzas de sus miembros, y las segundas a una solidaridad de tipo orgánico, es decir, diferenciada en partes funcionales especializadas cuya coagulación se lleva a cabo por su complementariedad y dependencia mutua. La solidaridad mecánica, en correspondencia con el derecho represivo, vendrá definida como aquella cuya ruptura constituye el crimen, es decir, la separación de la comunidad de origen, y cuya única forma de «religación», vendrá posibilitada por la expiación purificadora de la administración punitiva. El mantenimiento de la identidad comunitaria (Conciencia Colectiva), como fuente de la cooperación por semejanzas, será la primera necesidad social, que se impondrá sobre el individuo como una rígida disciplina de naturaleza moral y «sagrada». Por la otra parte, la solidaridad orgánica tiene un carácter negativo que se manifiesta en la sanción restitutiva como un «volver a poner las cosas en su sitio», es decir, como reparación de una lesión causada por la ruptura de un pacto contractual de intereses entre agentes privados. Este tipo de solidaridad ya no buscará la cooperación voluntariamente, sino tan sólo un pacto simbiótico bajo el principio de equidad o Justicia. Durkheim dirá al respecto de esta solidaridad negativa que «no es una perfecta solidaridad, con una existencia propia y una naturaleza especial, sino más bien el lado negativo de toda especie de solidaridad. La primera condición para que un todo sea coherente es que las partes que lo componen no se tropiecen con movimientos discordantes. Pero esa concordancia externa no forma la cohesión, por el contrario, la supone. La solidaridad negativa no es posible más que allí donde existe otra, de naturaleza positiva, de la cual es, a la vez, la resultante y la condición» ${ }^{1}$.

El presupuesto fundamental que guía a Durkheim en La división del trabajo social no es otro que la insuficiencia de una solidaridad nacida de la división del trabajo para mantener la cohesión social,

1 Ibid., p. 141. 
abanderando la necesidad de un consenso normativo básico como aglutinante de la socialidad humana, es decir, como predisposición del hombre a vivir en sociedad. El gran problema de Durkheim, llegados a este punto, es el mantenimiento de ese centro simbólico-totémico, tal y como se perfila en Las formas elementales de la vida religiosa, que imante a sus átomos sociales bajo el poder arquetípico de sus representaciones colectivas, gestoras de una identidad común y única fuente legítima de normatividad social. En principio, bajo el presupuesto del consenso normativo básico manifiesto en el derecho represivo, quedaría garantizada su existencia por encima de cualquier otra contingencia, pero transcendiendo la pura normatividad social y desplazándonos hasta la dimensión simbólica como ordenadora de la realidad y legitimadora de dicha normatividad legal, el diagnóstico adquiere un corte más weberiano, con diferentes formas de legitimación de la Autoridad pública y la progresiva fragmentación de la Conciencia Colectiva a tenor de los procesos históricos de racionalización sociocultural.

En este contexto, se puede decir que el gran hallazgo de Max Weber en La ética protestante y el espíritu del capitalismo es el de plantear una separación entre la moral, como sustrato simbólico de sentido en el camino de salvación, y la ética, como técnica de la práctica de salvación, abismo que habría permitido a la racionalidad ocupar su propio nicho dentro del ethos social; en definitiva, una ruptura entre los presupuestos bajo los cuales se organiza la normatividad y su esencia simbólico-identitaria, de la que, en hipótesis, ha nacido. Weber planteará la separación entre ambas como la culminación de un proceso de «desencantamiento del mundo», que conlleva inherentemente una «racionalización» de los afectos depositados en la práctica ritual comunitaria. En definitiva, una separación de los fines religiosos de salvación y de la práctica metódica del protestantismo ascético (orientada hacia el autoconvencimiento del individuo de su estado de gracia), del ethos profesional de la práctica metódica y de la «vocación» religiosa que lo sustenta. A este proceso Weber lo denominará «secularización», producida precisamente por las contradicciones internas de la moral calvinista, que por una parte reconoce el bien social de la creación de riqueza a través del trabajo, y por otro lado no tolera el empleo de dicha riqueza para el bienestar propio. Weber recoge las preocupaciones de uno de los pastores del protestantismo ascético en torno a esta paradoja: «Yo temo: donde la riqueza aumenta, la religión disminuye en medida idéntica... Los metodistas son en todas partes laboriosos y ahorrativos; de consiguiente, aumenta su riqueza en bienes materiales. Por lo mismo, crece en ellos la soberbia, la pasión, todos los antojos de la carne y del mundo, el orgullo de vi- 
vir. Subsiste la forma de la religión, pero su espíritu se va secando paulatinamente» ${ }^{2}$.

Daniel Bell le sacará partido a esta paradoja weberiana inicial hasta formularla, en su obra Las contradicciones culturales del capitalismo, como la oposición entre dos tipos de moral, entendida ésta desde el punto de vista de la integración. Así, frente a una moral del trabajo, todavía patente en la sociedad americana hasta la llegada de la sociedad de masas, se posiciona en la actualidad una moral existencial-hedonista, bajo la lógica del consumo masivo. Bell afirmará al respecto: «En el temprano desarrollo del capitalismo, el impulso económico sin freno fue controlado por las restricciones puritanas y la ética protestante. Se trabajaba por la obligación de cada uno a su propia vocación o para cumplir con la norma de la comunidad. Pero la ética protestante fue socavada, no por el modernismo, sino por el propio capitalismo. El más poderoso mecanismo que destruyó la ética protestante fue el pago en cuotas, o crédito inmediato. Antes, era menester ahorrar para poder comprar. Pero con las tarjetas de crédito se hizo posible lograr gratificaciones inmediatas. El sistema se transformó por la producción y el consumo masivos, por la creación de nuevas necesidades y nuevos medios de satisfacerlas», y más adelante: «El hedonismo, la idea del placer como modo de vida, se ha convertido en la justificación cultural, si no moral, del capitalismo» ${ }^{3}$. Paralelamente a este relevo, Bell augura un desacoplamiento entre el orden político, la estructura social y la cultura. Sin embargo, no considera la posibilidad, tal y como lo hará Habermas, de una doble integración: sistémica, en lo que al orden político y la estructura social se refiere, y social, en el plano cultural y de los estilos de vida (Mundo de la Vida). Es en este punto donde nos resulta obligado para el análisis de la integración el adentrarnos en los complejos estructurales de las teorías sistémicas planteadas por Habermas.

Como no podía ser de otro modo, Habermas hace partir su estudio de los sistemas sociales desde los anteriores trabajos de la escuela funcionalista, y más concretamente de T. Parsons. En el análisis de este autor consigue discernir dos programas diferentes a través de los cuales va orbitando su obra, como son el programa de «acción social», en la tradición idealista, y el programa «sistema social», dentro de la tradición positivista. Define estos dos programas teóricos del siguiente modo: «El programa "acción social" se centra en el significado que una acción tiene para un actor, mientras que el programa "sistema social" se centra en las

2 Ibid., p. 250.

3 D. Bell (1989), p. 33. 
consecuencias que una actividad tiene para un sistema de actividad» ${ }^{4}$. Habermas asegurará que, aun en el desarrollo de su teoría de la acción, Parsons no se interesará tanto por la hermenéutica, acercamiento al problema de la compresión de los participantes en la acción, como por los componentes normativos de la misma, en los que ya se pondría de manifiesto la perspectiva externa de un observador, más fielmente representativa de la teoría de sistemas. Con este presupuesto de partida, nos dirá que Parsons «...pierde de vista el genuino interés metodológico de la cuestión de si la teoría de sistemas ha de integrarse en y subordinarse a la teoría de la acción» ${ }^{5}$.

En definitiva, y según nuestra propia exposición, Parsons va a retomar el diseño durkheimniano sin analizar en todas sus consecuencias la separación entre el manejo de estructuras simbólicas de significado en la esfera de la acción y los patrones normativos directrices de la organización social; es decir, que presupondrá una armonía elemental entre ambas esferas, la simbólica-cultural y la normativa. Habermas proseguirá su estudio de la acción social en Parsons tratando de responder en su nombre a la pregunta de cómo es posible el establecimiento del orden social, refrendando la suposición anterior del peso del legado durkheimniano en su construcción teórica: «(Parsons) Hace suya la idea de Durkheim de que las acciones de una pluralidad de actores sólo pueden quedar suficientemente coordinadas sobre la base de normas reconocidas intersubjetivamente. Esta integración social exige de los actores individuales respeto a una autoridad moral en la que pueda apoyarse la pretensión de validez de las reglas de acción colectivamente vinculantes» ${ }^{6}$.

Antes de adentrarse en la más genuina construcción sistémica, un paso intermedio que Habermas intuye en Parsons es el de resituar la anterior teoría de la acción, entendiendo que ésta sufre una reorientación como producto de la cooperación mutua y sincrónica entre la cultura, la sociedad y la personalidad: «Parsons inicia ahora su construcción con el concepto de cultura y explica los sistemas de acción «sociedad» y «personalidad» como encarnaciones institucionales y anclajes motivacionales, respectivamente, de patrones culturales. Las unidades elementales ya no son las unidades de acción, sino los patrones culturales o los significados simbólicos» ${ }^{7}$. Serán fruto de esta inquietud

\footnotetext{
4 J. HABERmas, (1988), p. 284.

5 Ibid., p. 289.

6 Ibid., p. 293.

7 Ibid., p. 306.
} 
las conocidas pattern variables of value orientation, donde los valores culturales actuarán como patrones para una elección entre alternativas de acción, determinando las preferencias del actor sin que por ello se vea afectada la contingencia de sus acciones.

El paso definitivo a la teoría de sistemas se llevará a cabo cuando Parsons deje de reivindicar para el sistema cultural un estatus especial en la construcción del orden social. Al importar parte de las categorías de la teoría general de sistemas va a replantearse las relaciones existentes entre los valores, las normas, los fines y los recursos, reestructurando cada uno de estos «componentes de la acción» como un subsistema parcial, al que corresponderían recíprocamente la cultura, la sociedad, la personalidad y el sistema comportamental ${ }^{8}$. A cada uno de estos sistemas les va a corresponder una función determinada, como son el mantenimiento de patrones en la cultura, la integración en el sistema social, la consecución de fines en la personalidad, y la adaptación en el organismo comportamental. Lo más importante en este caso es que con el concepto de «sistema de acción» van a desaparecer los actores como agentes de la acción social, entrando, sin posibilidad de retorno, dentro de la más pura perspectiva sistémica.

Pero volviendo al tema de la integración que nos ocupa, Habermas nos dirá al respecto: «Parsons toma la importante decisión, que en ningún momento hace explícita, de renunciar en adelante al concepto de integración social de los contextos de acción, es decir, de integración de los contextos de acción, producida a través de valores y normas, y de no hablar ya sino de integración en sentido general» ${ }^{9}$. La trascendencia de esta decisión reside en que la integración pierde su carácter normativo durkheimniano para adentrarse en su función sistémica, que respondería más bien a las necesidades de coordinación; es decir, que desde este planteamiento se puede empezar a hablar de una integración sin atributos «morales», o si se prefiere al caso, puramente «funcional». En este sentido, Habermas nos adelantará que «Los imperativos funcionales en que ahora se especializa la "comunidad societal" pueden seguir cumpliéndose, ciertamente, por la vía del consenso normativo; pero precisamente en las sociedades modernas los ámbitos caracterizados por una "socialidad vacía de contenido normativo" se dilatan hasta tal punto que la necesidad de integración tiene que ser

8 En clara alusión a Luhmann, Habermas resaltará que «Los sistemas parciales constituyen entornos los unos para los otros, pero mantienen entre sí relaciones de intercambio reguladas» (Ibid., p. 341.). Es decir, que los sistemas no están cerrados los unos para los otros, sino que mantienen una relación de intercambio mutuo.

9 Ibid., p. 344. 
crecientemente satisfecha eludiendo el mecanismo del entendimiento» ${ }^{10}$.

Esta será precisamente la conclusión que Habermas hará suya de toda la exploración realizada en torno a Parsons, la de encontrar esos medios de comunicación del intercambio intersistémico que superen las estructuras de la intersubjetividad lingüística, más propia, esta última, de una integración normativa-valorativa. Parson distingue cuatro «medios de control», cada uno de ellos correspondiente a uno de los subsistemas principales según su función: el «dinero» al subsistema adaptativo-económico, el «poder» al subsistema de consecución de fines-político, la «influencia» al subsistema de la integración social-sociedad, y el «compromiso valorativo» al subsistema del mantenimiento de patrones estructurales-cultura. Sin embargo, lejos de aceptarlos tal cual, Habermas polemizará en torno a la posibilidad de generalización del concepto de medio para todas las funciones sistémicas apuntadas por Parsons, pues si en cuanto al dinero y al poder se podría aceptar su independencia de estructuras lingüísticas, en los otros dos medios apuntados no cabría realizar, desde la estrategia «comunicativa» que adopta Habermas, dicha suposición.

Resumiendo: cuando Habermas analiza el tema de la integración desde la óptica de la búsqueda de consenso en la comunicación, no puede dejar de darse cuenta de que ésta se realiza desde dos «canales» comunicativos diferenciados, como son el lenguaje para la integración social y la cultura, y los medios especializados de comunicación «dinero» y «poder» para el sistema económico y político respectivamente. Sin embargo, al dar el siguiente paso de ensamblar la integración social y la cultura en una misma esfera, como lo será su conceptualización del Mundo de la Vida, la composición sistémica heredada del funcionalismo se va a reducir únicamente a las funciones capaces de trascender la comunicación lingüística en la búsqueda de consenso, es decir, el sistema económico y el sistema político.

Sin embargo, Habermas todavía mantendrá las dos funciones básicas de los anteriores sistemas parsonianos de cultura y sociedad bajo la categoría del Mundo de la Vida, como son la reproducción cultural y la integración social. De este manera, asegurará que «La reproducción cultural del mundo de la vida se encarga de que, en su dimensión semántica, las nuevas situaciones que se presenten queden puestas en relación con los estados del mundo ya existentes: asegura la continuidad de la tradición y una coherencia del saber que baste en cada caso a la

10 Ibid., p. 345. 
práctica comunicativa cotidiana. Esta continuidad y esta coherencia tienen su medida en la racionalidad del saber aceptado como válido» ${ }^{11}$. Por el otro lado, «la integración social del mundo de la vida se encarga de que las situaciones nuevas que se presenten en la dimensión del espacio social queden conectadas con los estados del mundo ya existentes: cuida de que las acciones queden coordinadas a través de relaciones interpersonales legítimamente reguladas y da continuidad a la identidad de los grupos en un grado que baste a la práctica comunicativa cotidiana. La coordinación de las acciones y la estabilización de las identidades de grupo tienen aquí su medida en la solidaridad de los miembros, lo cual se patentiza en las perturbaciones de la integración social, que se traducen en anomía y en los correspondientes conflictos» ${ }^{12}$.

Habermas, lejos del idealismo hermenéutico de una sociología comprensiva que disuelva toda la sociedad en mundo de la vida, resalta la importancia de plexos de cooperación no normativos y sus medios de control como mecanismos sistémicos que estabilizan complejos de acción no pretendidos mediante un entrelazamiento funcional de las consecuencias de acción. Propone, de esta forma, distinguir entre «integración social» e «integración sistémica», donde una se centra en las orientaciones de acción que la otra atraviesa operativamente ${ }^{13}$. De este

11 Ibid., p. 200. Es aquí donde Habermas comete el error de identificar dos conceptos diferentes importados desde la fenomenología, como son el acervo de conocimiento de la experiencia y el conocimiento teórico (Berger y Luckmann, 1989; Schütz y Luckmann, 1997). El primero hace alusión a ese conjunto de recetas prácticas que todos incorporamos en nuestra interpretación de la situación de acción y que se experimenta de forma natural y «rutinaria», es decir, sin llegar a la conciencia reflexiva. Un ejemplo desarrollado de este acervo de conocimiento práctico lo tendríamos en el concepto de habitus creado por P. Bourdieu (1991). El conocimiento teórico sería un paso posterior surgido de la tipificación de trascendencias, y que como material cognoscitivo supondría la base simbólica de legitimación y consenso oficial acerca de la realidad misma. Esta distinción entre ambos términos resulta capital para la comprensión de la distinción que más adelante se realizará entre dos tipos de culturas: una cultura expresiva y una cultura científica-oficial.

12 Ibid.

13 Resulta importante destacar que, desde el punto de vista del individuo, toda experiencia vital está alumbrada bajo el techo del Mundo de la Vida, y sólo en esta esfera social, como espacio de la percepción subjetiva, se puede configurar su «realidad». Por la otra parte, el atravesamiento operativo de los medios especializados de comunicación hace referencia a los mecanismos sistémicos que escapan a la experiencia, pero de los cuales también emerge una integración de corte «procedimental». Giddens hará referencia a estos últimos conceptualizándolos como una «experiencia secuestrada» (Giddens, 1994). Por su parte, tambien Luhmann se hará eco de este problema reclamando una «realidad» sistémica propia a la ciencia del conocimiento por sobrepasar al individuo como sujeto de la expe- 
modo, por una parte tendríamos la «integración social» en el Mundo de la Vida como la coordinación de las acciones sociales a través de la armonización de las orientaciones de acción; y por la otra parte, partiendo de una situación en que las orientaciones de acción difuminan sus referencias normativas, nos encontramos con la «integración sistémica», como el entrelazamiento funcional de agregados de acción no intencionales que convergen en estructuras transindividuales, más allá de la voluntad y de la conciencia de los actores individuales, y que hacen posible la coordinación de grandes grupos sociales sin las restricciones de la copresencia y los límites comunicativos del lenguaje. Como representación esquemática podemos observar el siguiente cuadro:

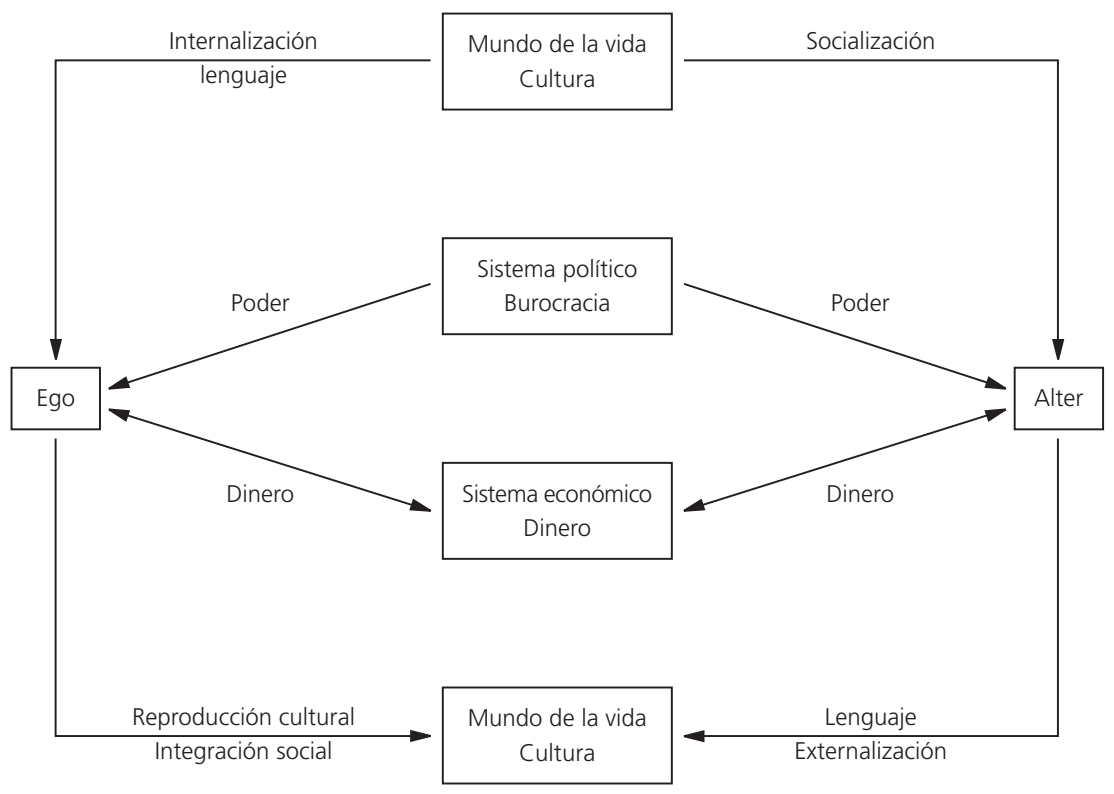

riencia del conocimiento, pues el conocimiento solamente tiene existencia en el flujo comunicativo (objetividad construida en la autorreferencialidad epistemológica —autopoiesis-): «No es necesario que una conciencia que tome parte en la comunicación piense en cada caso que la palabra "manzana" es un signo para referirse a una manzana ... Lo único que se requiere es que la autopoiesis de la comunicación resulte capaz de manejar una palabra como palabra, a la vez que como signo que se refiere a una información, delimitando de esta manera su esfera propia de frente - como podría pensarse - a lo que realmente existe como una manzana» (Luhmann, 1996, p. 23.). 
El primer dato que se nos hace visible en el esquema es un Mundo de la Vida que rodea toda la vida social, incluyendo a los entramados sistémicos político y económico, aunque estos últimos se mantendrían en un segundo plano que no tendría una relación directa con el Mundo de la Vida como «realidad» social. Este Mundo de la Vida se manifiesta además como algo dinámico, donde en un primer momento internaliza en el individuo una serie de patrones culturales como orientaciones de acción mediante un proceso de «socialización», y después se vuelve a constituir en el reencuentro de estos individuos socializados por medio de su interacción dentro de ese espacio del Mundo de la Vida, externalizando el acervo de conocimiento adquirido como propio a través de una personalidad social, y dotando con esta intersubjetividad consensuada a la realidad experimental su esencia objetiva y naturalizada.

Por el contrario, en lo que a la integración sistémica se refiere, lejos de clarificarse con el esquema se vuelve a poner en evidencia el excesivo carácter reduccionista de una integración realizada únicamente a través de medios especializados de comunicación. Y ello es así por dos razones. En primer lugar, si en el caso del «dinero» sí se puede constatar un lugar de encuentro entre ego y alter-ego, como tendría lugar en el mercado, ésta, sin embargo, no sería una facultad del medio «poder», que únicamente se desplazaría en una corriente descendente, desde la instancia del Estado político representado por unos funcionarios organizados burocráticamente. En este sentido, la normatividad social, sobre la que se asienta la legitimidad y los códigos operativos de este poder político, emerge como una instancia fuera de todo control, con personalidad propia y fuera de la acción de los individuos. Es más, sin ningún tipo de input desde el exterior que les ofrezca información sobre los temas relevantes y necesitados de reglamentación normativa desde el Mundo de la Vida, es decir, sin ningún tipo de contacto con el sistema cultural, ni tampoco con el sistema económico ${ }^{14}$. Y aquí arranca la segunda razón, esto es, el aislamiento e indiferencia de los sistemas entre sí; contando por sistemas únicamente el económico y el político, pues el cultural queda absorbido por el Mundo de la Vida.

14 Pese a la renuencia de Habermas a aceptar la clausura autorreferencial de los sistemas luhmannianos, vuelve a cometer el mismo error al dejar de lado el análisis input-output (medios-fines) de la ingeniería de sistemas (Luhmann, 1996, pp. 206, 218, 438, 449), para delimitar un sistema únicamente respecto a un canal comunicativo específıco con «realidad» propia, como resulta el medio poder para el sistema político (Luhmann, 1995, pp. 19 ss.). 


\section{Reciclando el problema de la integración}

Una vez realizada esta aproximación al problema de la integración desde el marco habermasiano, a continuación pasaremos a depurar su modelo para obtener uno nuevo que refleje de manera más comprensiva los mecanismos de integración en las sociedades modernas avanzadas.

El reduccionismo de la categoría de sistema en Habermas, limitado a las esferas de acción mediatizadas por el poder y el dinero y propiciado por su formulación desde una teoría de la comunicación polarizada en lenguaje/medios especializados, tendría en su haber otro sesgo de importancia capital, como es la reducción del sistema cultural únicamente a su dimensión expresiva-valorativa, dejando en la amnesia su propia explicitación del resto de las actitudes ordenadoras de la realidad, como son la «objetivante» hacia la naturaleza (racionalidad técnica-instrumental) y la «conformativa» hacia normas (ordenación de la comunicación-justicia). Estas tres actitudes, la expresiva, la conformativa y la objetivante, necesitan de sus respectivas culturas para manifestarse y hacerse conciencializables, si bien se podrían simplificar, por utilizar expresiones de la fenomenología, como acervo de conocimiento experiencial y conocimiento teórico-científico. La primera de estas culturas la vamos a seguir denominando «expresiva», por cuanto recoge las actitudes y marcos para las posibles interacciones sociales en el Mundo de la Vida; en cuanto a la segunda, en contraposición a esta cultura del sentido común, la vamos a denominar cultura científica, o incluso simplemente «ciencia», ya que en ella reposa la legitimidad para ordenar las «formas» apropiadas tanto en cuanto a la normatividad «positiva» se refiere como a la técnica oficialmente reconocida para su aplicación a la naturaleza. Es más, por mediación de esta cultura científica podremos volver a reivindicar su emplazamiento como sistema independiente del Mundo de la Vida, donde si el sistema político establecía la separación de roles entre funcionario y ciudadano, y el sistema económico la distinción entre ofertante y demandante, el sistema cultural-científico va a establecer el juego de roles entre el experto y el lego ${ }^{15}$. Es aquí, además, donde la diferenciación de subsistemas, como disciplinas de conocimiento autorreferenciales, adquiere

15 En esta división de roles hay que destacar que si en el sistema económico la relación entre ego y alterego se realiza «horizontalmente», al menos como igualdad reconocida legalmente (la desigualdad puede darse en los términos marxistas de poseedores de Capital y poseedores de Fuerza de Trabajo), tanto en el sistema político como en el científico esta igualdad no existe como tal, pues en las relaciones funcionario-ciudadano y experto-lego conllevan una subordinación del segundo a las directrices del primero (en el sistema económico ambas partes deben ponerse de acuerdo). 
sus rasgos luhmannianos más claros, pues deben proveer tanto al sistema económico, como al político, como así mismo al sistema de la cultura oficialmente reconocida, de los «expertos» en cada una sus especialidades temáticas ${ }^{16}$.

De este modo, el sistema científico, como proveedor de conocimiento oficialmente válido para el resto de los sistemas funcionales, no va a ocupar un emplazamiento social cualquiera, sino que se va a posicionar como el sistema central que regula, a través de su producción de conocimiento especializado, todos los demás sistemas. La única esfera que quedará libre de su abrazo disciplinante es el Mundo de la Vida, pues en ella son los individuos, como «sujetos» de la experiencia, quienes reclaman la potestad de crear y recrear su «realidad» a partir de una subjetividad compartida (intersubjetividad), en la que, dicho sea de paso, no tendrá tanta influencia la capacidad de análisis racional como la carga emocional y de sentido situacional ${ }^{17}$.

16 En este sentido, la autopoiesis de cada sistema, que discrimina mediante el criterio de verdad lo que está dentro y lo que está fuera (entorno), es tan sólo un artificio que funciona como un código director operacional, y no en cuanto al intercambio de materiales o de información, aunque los elementos incluidos como componentes del procesamiento interno operacional en los que se articulan dichos materiales e información sean única e intrasferiblemente propios de cada sistema. Jesús Ibáñez (1993), citando a Maturana y Valera, afirmará que «La autopoiesis es un caso particular de clausura organizacional. Los sistemas autopoiéticos son oganizacionalmente cerrados (se organizan a sí mismos, no están programados desde fuera) e informacionalmente abiertos (aprenden: son capaces de distinguir e indicar)». La denominación de «sistemas expertos» viene a conceptualizar mejor ese carácter cerrado y autorreferencial, e incluso esotérico, de los sistemas de conocimiento que regulan el entramado funcional, sin que por ello se «desnaturalice» la percepción de la «realidad subjetiva» de dichos materiales e información, aunque se procesen de diferente manera dependiendo del sistema experto en cuestión. Este será un problema que se analizará con más detalle en el apartado de conclusiones.

17 Aquí se nos abre la cuestión de, si para el individuo su existencia y realidad sólo tiene cabida en ese Mundo experiencial de la Vida, cómo pueden llegar a manifestarse en este Mundo de la Vida los sistemas expertos. Habermas tratará de solucionar esta cuestión a través de los medios generalizados de comunicación, por medio de los cuales se genera en la acción un residuo en forma de «experiencia secuestrada», que en última instancia emerge como un sistema propio y no intencional de las subjetividades particulares, pero con la capacidad de coordinarse y regularse a sí mismo (autopoiesis). El caso más ejemplar lo podemos encontrar en el medio dinero, donde en las transacciones de ego y alterego se crea una realidad de segundo orden en el puro flujo comunicativo de dicho medio, que por sus propias leyes de mercado (condensación de flujos en un tiempo-espacio propio al sistema, y ajeno a la acción presencial de ego y alter-ego) estipulará los términos de dichas transacciones. Por el contrario, frente a esta hipótesis de una «sociedad inconsciente», también podemos constatar la posibilidad de que el individuo «represente conscientemente» a dichos sistemas expertos, a través de la asunción de roles funcionales. Es bajo esta última solución donde es posible distinguir roles estereotipados que permitan diluir, en la estandarización 
Hecha esta diferenciación entre el Mundo de la Vida, con su acervo de conocimiento experiencial, y «sistema» cultural científico, es decir, la cultura como sistema autónomo de conocimiento, con sus instrumentos internos de regulación, desarrollo y entidad jurídica (institutos) $)^{18}$, vamos a pasar a reformular el esquema legado por Habermas con la intención de proponer un nuevo modelo de la integración social y sistémica en la modernidad.

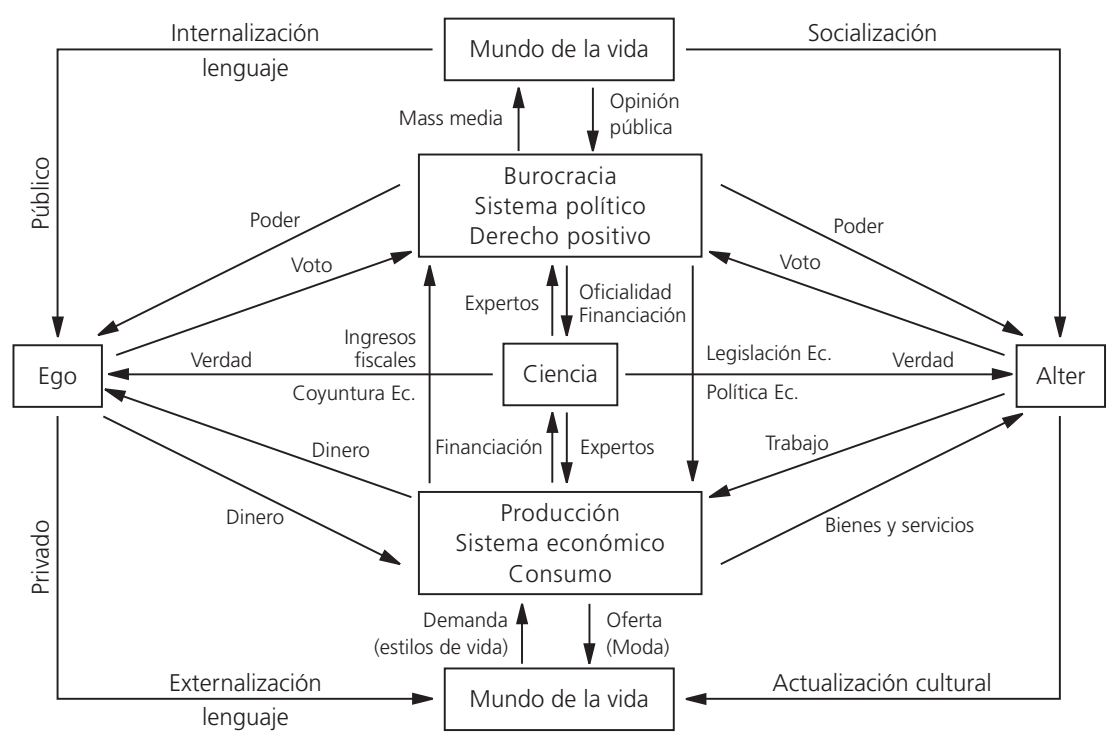

de sus relaciones bajo un código de comunicación, la carga de una búsqueda lingüística de consenso comunicativo, y donde además se van a poder establecer relaciones de subordinación en torno a la autoridad del conocimiento experto como garantía última de la validez del sistema (la autoridad actuaría como un referente de confianza emocional «seguridad ontológica» en la «realidad» y la validez operativa del sistema), Giadens (1997), pp. 81-98.

18 Dentro de este contexto se podría situar también la diferenciación que realiza P. Bourdieu (1991) entre Capital cultural y habitus. El primero haría referencia a la inversión realizada en formación oficial, es decir, la cualificación obtenida a través de institutos de enseñanza de la cultura científica; el segundo es aquel conocimiento adquirido en la práctica del Mundo de la Vida, íntimamente asociado a las «maneras» y el gusto, que definen los estilos de vida de las clases sociales. La paradoja a la que hace referencia Bourdieu, al analizar a las clases medias, es su pretensión de adquirir un habitus de clase alta a través de su inversión en cultura oficial, es decir, tratan de adquirir una práctica naturalizada de un estilo de vida mediante su mero reconocimiento obtenido en la cultura oficial, quedándose tan sólo en eso, en la pretensión de distinción social. 
Como se muestra en este nuevo esquema, lejos de mantenerse los sistemas aislados unos de otros, interaccionan entre sí intercambiándose en inputs y outputs. Así, el sistema económico provee al político de una coyuntura del estado actualizado de sus transacciones, en forma de macromagnitudes, a las que el sistema político reacciona con una serie de políticas económicas que regulen dichas transacciones para acortar sus ciclos depresivos (siempre que la crisis fiscal lo permita). Por otro lado, con las regulaciones normativas del derecho positivo también el sistema político actuaría en el económico poniendo los límites para sus transacciones, del mismo modo que el económico condicionaría al político en un mayor o menor flujo de ingresos por la vía de la «fiscalidad» impositiva (esto no niega la posibilidad de la emisión de deuda pública). Respecto al Mundo de la Vida, en primer lugar, interfiere en el sistema económico como una resistencia a la planificación racional de la producción ${ }^{19}$, viéndose interferido por la racionalidad económica en el consumo, como la imposición objetivada de una moda con la que crear estilos de vida. Por la otra orilla, respecto a la política, el Mundo de la Vida influye en ella por intercesión de la «opinión pública» creada en su seno ${ }^{20}$, pero, al mismo tiempo, este consenso generalizado de interés público se ve instrumentalizado a través de los Mass Media. En cuanto a la ciencia, aportaría tanto al sistema político como al económico de los expertos y su actualización continua en los conocimientos especializados que les competen; así como estos dos sistemas contribuirían a su vez para con la ciencia con los fondos necesarios para su desarrollo, a lo que abría que añadir, por parte del sistema político, el reconocimiento oficial o garantía legítima de los títulos oficiales de enseñanza y el apoyo de sus institutos. La diferencia fundamental entre los institutos de investigación y desarrollo públicos y privados residiría en que, si el primero sólo tiene en cuenta los rendimientos científicos, como puede ser el caso de las investigaciones absolutamente teóricas de las universidades o de los

19 El redescubrimiento del lado humano en las empresas tuvo lugar en el experimento de Hawthorne llevado a cabo por Elto Mayo entre 1927-1932. En dicho experimento se evidenció que las redes informales de los trabajadores, así como sus motivaciones personales de autorrealización, creaban una resistencia para con el trabajo planificado racionalmente, que era menester incorporar al diseño organizacional. A partir de esta primera escuela de relaciones humanas se irán desarrollando diferentes enfoques que tratarán de asumir el reto de incorporar la lógica del Mundo de la Vida a la cultura propia de la empresa, de los cuales el que mayor prestigio tiene en la actualidad es el vertebrado en torno a la «Calidad Total».

20 Otra posibilidad de influencia resulta de las redes informales de comunicación, por las cuales se pueden transmitir orientaciones estratégicas de acción que coordinen los intereses corporativistas y personales de un círculo social restringido (elite). 
ingentes capitales destinados a la investigación militar para encontrar una ventaja armamentística frente a otros competidores, el segundo se encargaría más bien de buscar las aplicaciones tecnológicas para la satisfacción de necesidades del Mundo de la Vida, guiados por la rentabilidad económica y la ventaja competitiva de la reducción de costes e incremento de la calidad.

En este esquema también podemos apreciar cómo el Mundo de la Vida, escenario de la comunicación intersubjetiva de sentido lingüísticamente mediada, sigue constituyendo la realidad social por excelencia, rodeando con su abrazo de la vida experiencial al resto de las realidades de segunda generación, por utilizar un término de Malinowski o sistémicas. El círculo dinámico de este Mundo de la Vida seguiría siendo aquel que va desde la socialización en diferentes grupos sociales y sus representaciones simbólicas, hasta su «actualización» cuando dichos individuos socializados se reencuentran en la interacción social. Se han sustituido las funciones de la reproducción cultural y la integración social por el término «actualización» para resaltar no solamente una reproducción de estructuras, sino también la posibilidad de que surjan nuevas estructuras que se adapten mejor a las nuevas situaciones y retos, tal y como pudiera sugerir el lema del proyecto de la modernidad, llevado al extremo por las vanguardias artísticas, como «renovación sin fin».

En cuanto al entramado sistémico de este complejo social se refiere, comenzaremos por resaltar, una vez más, el papel central de la Ciencia como dispensador, oficialmente autorizado y socialmente legitimado, de la Autoridad simbólica y moral. Como el mismo Durkheim entrevió en su época, analizando los diferentes elementos de la civilización, sólo la ciencia poseería un cierto carácter moral, puesto que «las sociedades tienden cada vez más a considerar como un deber para el individuo el desenvolvimiento de su inteligencia, asimilando las verdades científicas establecidas.... todo el mundo está obligado a no permanecer ignorante. Esta obligación hállase incluso tan fuertemente sentida que, en ciertas sociedades, no sólo se encuentra sancionada por la opinión pública sino por la ley» ${ }^{21}$.

La ciencia, como creadora de conocimiento por mediación del cual se ordena la «realidad», rompe la idea pre-ilustrada de un orden «revelado» por inspiración divina, usurpando la prerrogativas sagradas de dicho orden (de carácter normativo y restrictivo para individuo), y confiriéndose a sí misma la «pretensión de validez» en torno a la refutación

21 E. Durkheim (1995), p. 60. 
experimental de sus diseños racionales. El hombre ya no aparece como fideicomisario de un mundo creado y ordenado trascendentemente, sino que reclama su madurez como organizador de una Naturaleza rendida ante los logros de su «razón». La nueva moral, nacida de este impulso racional emancipatorio, sólo puede tener en el «trabajo»su espacio de realización, y será sobre el cual el mismo Weber sondeará buscando un doctrina religiosa que lo apoye y legitime como camino de salvación antes de su secularización ${ }^{22}$.

Pero al mismo tiempo, estas pretensiones de legitimación de orden basadas en el conocimiento científico van a crear una ruptura en el concepto mismo de cultura, pues si hasta este momento se le había asociado una carga de distinción social en torno a esas «castas» o estamentos aristocráticos que por verse absueltos del trabajo, entendiendo éste únicamente como trabajo manual dirigido a la supervivencia, podían permitirse el lujo de recrearse en artificios intelectuales, a partir del asalto de la burguesía a la escena pública los conceptos de trabajo y cultura son trastocados, pues ambos quedarán asociados, presentándose la burguesía como aquella clase social que encarna ambos conceptos hasta entonces opuestos ${ }^{23}$.

Es en este escalón histórico en el que se sitúa el proyecto de la Ilustración, que frente a ese orden revelado que legitima un orden social estamental va a reivindicar el papel del hombre como constructor de su propio orden racionalmente diseñado. De este modo, si en el orden revelado la norma precede al orden, o éste debe su existencia a la norma (como expresión de una Conciencia Colectiva, de carácter predominantemente religioso), en la construcción racional se parte de la premisa de la necesidad de orden para llegar, a través de un «Contrato social», a establecer un «consenso» en normas que estructuren dicho orden ${ }^{24}$.

22 Cabría especular si la ética protestante es una causa o un efecto de este proceso de racionalización, es decir, si el éxito de sus miembros en el capitalismo emergente se debió a ser los motores del proceso de racionalización o simplemente los beneficiarios de dicho proceso, en el que tan sólo habrían colaborado colateralmente. De ser así, habría que volver a buscar los elementos «seculares» de dicha racionalización, sin prestar atención ya a un origen religioso, tal y como por ejemplo hizo Saint Simon como profeta de la «tecnocracia».

23 D. Bell (1992), p. 26.

${ }^{24}$ El concepto de Contrato social tiene aquí una mayor herencia de Rousseau que de Hobbes, ya que este último vino a desconfiar de la buena disposición de los hombres para buscar un consenso voluntariamente, y sólo la proyección del instinto de preservación natural en la razón le daría la suficiente fuerza a ésta frente al resto de elementos pasionales para renunciar a su libertad natural y sujetarse a la Autoridad de un ente social representado en la figura del soberano. 
Locke recogerá estas inquietudes políticas para presentar un proyecto viable de democracia liberal ${ }^{25}$. Estas ideas en torno a la voluntad racional inalienable del individuo que participa en el Contrato Social, junto con el universalismo kantiano de la moral como autocontención racional, pondrán las bases para la superación definitiva del orden tutelar aristocrático-revelado, donde lo comunitario-afectivo va perdiendo fuerza frente a la doctrina del individualismo racional autorresponsable. A partir de la emergencia social de este ideario como hecho social consumado, especialmente presente en la confluencia masiva de población en las ciudades por efecto de la industrialización, los avispados sociólogos de la época empezarán a hablar de una sociedad como mera «asociación», donde los individuos entran en interacciones cooperativas como fusión de intereses comunes y/o complementarios ${ }^{26}$.

El último paso de este proyecto de modernidad será cuando muestre sus propios defectos ${ }^{27}$. Al ser el orden un diseño facturado por el hombre, su pretensión de validez racional quedará siempre sujeta a crítica, y, en consecuencia su «verdad científica», susceptible de modificación o incluso de desaprobación, devendrá siempre contingente. Además, al incrementarse los campos de aplicación científica con sus cuerpos teóricos especializados, cada vez se incrementa en mayor medida su «contingencia», pues con la multiplicación de competencias disciplinarias como motor reductor de «complejidad», en la autorreferencialidad de sus propias lógicas operativas los riesgos derivados de la falta de coordinación entre ellas se incrementarán al mismo ritmo que sus avances en conocimiento especializado. Lejos de restringirse estos efectos de la compartimentación disciplinaria del conocimiento a su universo propio de la cultura científica, con la exportación de los «expertos» al resto de los entramados sistémicos se expandirá como una plaga esta crisis de confianza en la racionalidad, prolongación de la fe depositada por el viejo proyecto de la Ilustración en un progreso indefinido, poniendo en jaque a todo el sistema social en su conjunto reconstruido bajo

25 En la tradición inglesa este paso entre orden aristocrático y orden democrático no habría resultado tan abrupto como en otros países por sucederse de manera gradual, desde una cámara de lores a otra de comunes, en la que de forma progresiva se fueron incorporando nuevas clases sociales conforme demostraban su madurez de ciudadanos con su competencia para aceptar la doctrina racional (instrucción).

${ }^{26}$ F. TÖNNIES (1979).

27 Una obra de consulta obligada sobre este particular es la recopilación realizada por Josetxo Beriain (1996) en Las consecuencias perversas de la modernidad. En ella podremos encontrar las reflexiones de autores de la entidad de Giddens, Bauman, Luhmann y Beck sobre esta «modernidad contingente». 
los presupuestos del control racionalmente planificado. U. Beck analiza este proceso como una «modernidad reflexiva» que despierta en el seno de una «sociedad del riesgo», que no hace sino poner al descubierto los efectos colaterales y no deseados de una racionalidad que, por su naturaleza fragmentadora del conocimiento especializado, sólo puede ser imperfecta en su vocación domesticadora de naturaleza (como lo manifestarían los riesgos ecológicos). Desde esta perspectiva, el Mundo de la Vida aparece como el «entorno» donde confluyen los «riesgos» (que entrañan las diferentes tomas de decisiones de los «sistemas» expertos) como «peligros» reales para la vida, y donde en consecuencia tendría lugar ese redescubrimiento reflexivo de lo político, manifiesto en la figura del contraexperto frente al experto sistémico (por ejemplo en los nuevos movimientos sociales como Greenpeace).

A la hora de organizar y diferenciar el resto de sistemas, se va a trazar una línea divisoria entre lo público y lo privado. Lo público abarcaría a una parte de la cultura del mundo de la vida (aquella que se conoce como Opinión Pública), al sistema político por entero, y a aquella parte de la cultura científica que fuese de dominio público, como por ejemplo la dispensada en la enseñanza obligatoria. Sin embargo, lo que realmente otorgará la etiqueta de la relevancia pública es la visualización de cualquier tema en el escenario colectivo, sin menoscabo de su procedencia sistémica o del Mundo de la Vida, por intervención de los Mass Media $^{28}$. En contraposición, en la esfera de lo privado encontraríamos a la mayor parte del Mundo de la Vida, al menos aquella que por su involucración experiencial se considera más cercana y «real», al sistema económico, aunque aquí con grandes matices, y a aquella parte de la ciencia que no es de dominio público, es decir, que queda restringida a los diferentes círculos de expertos que monopolizan el conocimiento especializado en un campo de aplicación ${ }^{29}$.

28 Más adelante analizaremos el papel desempeñado por estos Mass Media como sustitutos modernos de la Conciencia Colectiva «simbólica», representada en las sociedades primitivas por ese espacio social público-colectivo centrado en torno a un tótem .

${ }^{29}$ Fíjese el lector en la diferencia respecto al monopolio de la cultura que pudiera tener el cuerpo eclesiástico durante la Edad Media, pues entonces una organización compacta de eruditos, unidos por los límites de una misma doctrina sagrada y con conciencia de su papel corporativo dentro de la sociedad, podía estar en posesión de la cultura relevante para todos los campos de actividad, o al menos para los que importaran en la reproducción social; y en cambio en la modernidad, la Autoridad simbólica del conocimiento legítimo aparece fragmentada, de forma tal que el mayor experto en un campo de aplicación resulta un lego para cualquier otra disciplina de conocimiento, y, en consecuencia, totalmente dependiente respecto al resto de las aplicaciones de conocimiento especializado. Es por ello altamente difícil poder hablar de una posible «revolución de los expertos», como pudiera ha- 
Empezando por la economía, se puede resaltar su doble naturaleza privada-pública: por un lado, en su función primigenia para la satisfacción de necesidades, localizada en el Mundo de la Vida de donde surgen y se satisfacen, tendría un carácter privado; pero por el otro lado, en cuanto la economía empieza a crear sus propias necesidades «sistémicas» para la coordinación de los entramados de intercambio, la aplicación de la tecnología a la producción, la organización del trabajo, etc., empieza a mostrar también su rostro social, manifiesto, principalmente, en un Capital como recursos adaptativos generados colectivamente (acumulación del medio dinero). Recurriendo a la teoría marxista, encontramos el origen de este Capital en la plusvalía, que aparece cuando «una determinada sociedad es capaz de producir más de lo suficiente para la satisfacción de sus "necesidades vitales" ${ }^{30}$, es decir, como aquella parte del «valor de uso» ofrecido por el trabajador al Capital en su contrato de trabajo que no es recogido como «valor de cambio», esto es, como el precio de la mercancía «fuerza de trabajo» en el justo valor de los medios de subsistencia necesarios para su reproducción (incluida la descendencia, y según el estado de unas necesidades determinadas culturalmente). Weber también desvela esta naturaleza social del Capital en La ética protestante y el espíritu del capitalismo, cuando al hablar sobre el espíritu del capitalismo como «afán de lucro» retoma las máximas morales legadas por Benjamín Franklin, antes de ser desvirtuadas en sentido utilitarista, para concluir que «...lo característico de esta filosofía de la avaricia es el ideal del hombre honrado digno de crédito y, sobre todo, la idea de una obligación por parte del individuo frente al interés - reconocido como un fin en sí- de aumentar su capital» ${ }^{31}$. El compromiso que contrae el tomador de un crédito es devolverlo con unos intereses, y con el trabajo como única vía legítima para hacerlo. Pero este compromiso de ser productivo, de forma que el capital invertido pueda ser devuelto con sus intereses, es ante todo un compromiso social, en el que el individuo se impone como un deber «moral» el ser útil al resto de la colectividad, manifiesto materialmente en la forma de una contribución al conjunto de los recursos colectivos (Capital)

cerse con las tesis de la «inteligentsia» (Trotski) o la propia «revolución de los Gerentes» (J. Burnham), pues salvo para mostrar el vértigo que produce la especialización de conocimiento y la cada vez mayor importancia que puede tener en la reproducción y desarrollo de los sistemas, resulta del todo inapropiado para referirse a una nueva clase «para sí». Ver Castells (1995 y 1997); Eco, Colombo, etc. (1995).

30 A. Heller (1995), p. 23.

31 M. WEBER (1995), p. 45. 
para nuevas inversiones productivas que redunden en el bienestar común. La paradoja aquí, sobre la cual se articularán los proyectos socialistas, es que siendo unos recursos generados colectivamente, gracias al conjunto de plusvalías arrancadas al factor trabajo, permanecen bajo la forma de la propiedad privada ${ }^{32}$, y en consecuencia, fuera del control «consciente» de los intereses colectivos organizados políticamente $^{33}$.

Por lo que al sistema político se refiere, lo primero sería señalar las limitaciones del modelo habermasiano, únicamente construido en torno al medio especializado de comunicación del «poder». Desde esta perspectiva, es el individuo el que se despersonaliza como un simple

32 En la actualidad, en plena «globalización económica», esta contradicción entre intereses privados y públicos es todavía más acusada, pues el capital es un capital internacional, no sujeto a las restricciones de las comunidades nacionales. Este es uno de los grandes problemas sociales que los contemporáneos Estados de Bienestar tratarían de solventar, pero que al mismo tiempo los pondrán en una crisis fiscal constante, pues el Capital de inversión se desplaza hacia las situaciones de rentabilidad más ventajosas, como en la cuestión del precio de la Mano de Obra serían los países en desarrollo, no respetando los intereses colectivos, tales como la necesidad de empleo nacional.

${ }^{33}$ La utopía marxista tratará, precisamente, de fusionar ambos aspectos bajo la misión redentora de una clase social que represente los intereses colectivos. Es utópico porque confunde las propias necesidades de organización y estructuración social con un presupuesto filosófico idealista heredado de Hegel, como es la reapropiación del mundo construido socialmente mediante el desemascaramiento de su inmediatez reificada (cosificación en Luckaçs) en virtud de una «racionalidad reflexiva». El proletariado, como sujeto histórico, encarnaría en su esencia la misión de unir la teoría (ideal filosófico) y la praxis (revolución política emancipatoria), de poner en marcha un nuevo modelo social comunitario-solidario en el que el hombre se pueda autorrealizar asumiendo la naturaleza socializada de su trabajo, y no bajo el yugo reificado de su propia creación. En definitiva, donde el Mundo de la Vida, como espacio de manifestación de la «integridad» de la esencia humana, asumiría como propio todos los entramados sistémicos por los que se organiza la vida social (de ahí la «racionalidad reflexiva», empezada por Marx en El Capital y continuada por la escuela de Frankfurt, como una ciencia que «desvele» los mecanismos sistémicos reificados y que haría posible la concienciación, apropiación y control social de las estructuras dinámicas «invisibles»). Sin embargo, el comunismo fracasaría en estas pretensiones precisamente por no ser capaz de llevar a cabo la tarea de humanizar, o hacer accesible al conjunto de la población, el conocimiento especializado de los sistemas expertos, es decir, de construir una población sabia o experta capaz de asumir eficientemente las tareas de autogobierno, incluyendo en las mismas la propia organización económica. Como diría Alain Minc (1994, p. 117): «El comunismo aplastó la razón por querer encarnarla hasta sus últimas consecuencias». Las planificaciones económicas de las necesidades de la población y la dirección de los «recursos sociales» para satisfacerlas en la producción, siempre se han mostrado excesivamente rígidas, cortando la motivación personal de aquellos organizadores del factor trabajo, papel desempeñado en el capitalismo por los empresarios, para dar respuesta a las nuevas necesidades, o incluso crearlas, en el Mundo de la Vida, y que funcionan como motor del progreso tecnológico bajo la directriz de la competencia. 
número en la «gestión» burocrática de los recursos humanos, respondiendo incluso a las características de medio que reunía el dinero respecto a los recursos adaptativos, tales como ser medible (variables demográficas), acumulable (dentro de una población, como municipio u otras categorías administrativas territoriales), e intercambiable (por ejemplo entre municipios). La burocracia es la forma moderna en que el hombre se consume simbólicamente a sí mismo, y la ley su nuevo sacerdocio. El individuo pierde su identidad personal en favor de su identificación administrativa: no es consultado sino tan sólo contabilizado como un recurso o carga social, y como tal considerado en los organismos de control colectivo para entrar en filas, su aportación fiscal, la necesidad de servicios sociales, las dotaciones de infraestructuras, o para su participación electoral. Aunque esta última tendría su propia entidad, pues en sí mismo el «voto electoral» es otro medio especializado de comunicación, pues gracias a él los recursos humanos se agrupan «mecánicamente» en torno a un programa de gobierno. Es un medio especializado de comunicación porque el único lugar de encuentro entre Ego y Alter-ego es una urna, sin necesidad de que siquiera lleguen a tener un encuentro personal en el que «buscar el consenso», sino que éste se articula como un sumatorio de voluntades individuales en un programa, proporcionado, dicho sea de paso, desde la propia instancia del sistema político.

La relación con el Mundo de la Vida se lleva a cabo por mediación de la Opinión Pública, que recoge las necesidades sociales en forma de preocupación de interés general, a su vez mediatizada por los Mass Media. Estos ocupan un lugar central como filtro y constructores de «lo público», y por ello les vamos a dedicar una atención especial. Habermas entiende los Mass Media como «formas generalizadas de comunicación», que ya no sustituirían al entendimiento lingüístico, tal y como harían los medios especializados de comunicación, sino que simplemente lo condensarían, haciendo surgir espacios de Opinión Pública ${ }^{34}$. Sin embargo no se extiende en este particular todo lo que cabría esperar de un elemento tan importante en sus funciones como catalizador del consenso social e, incluso, como representante moderno de la Conciencia Colectiva en la sociedad de masas.

Los Mass Media intervienen en el caldero de voluntades individuales de la sociedad de masas iluminado, con su función mediadora, la pista central de la cultura expresiva «pública», diferenciándola de esas otras pequeñas pistas periféricas de la privacidad cotidiana. Son el

34 J. HABERMAS, op. cit., p. 552. 
gran proyector de lo que todo el mundo (de la vida) está observando en un momento dado, y por consiguiente, lo que tiene un interés general. Aun más, sólo cuando el proyector se gira sobre sí mismo, el mundo de la vida toma consciencia de sí en la vida pública, manteniéndose hasta entonces bajo las sombras de lo no concebido ${ }^{35}$. Es bajo este aspecto donde se empieza a mostrar la función de los Mass Media como representantes de la Conciencia Colectiva, dado, en primer lugar, que el reconocimiento en prensa, radio o televisión de alguna noticia demuestra que es lo suficientemente importante para atraer el «interés público» de entre la gran masa anónima de hechos intrascendentes. Pero es que, en segundo lugar, los Mass Media también transmiten normas de carácter moral, dando a conocer al gran público situaciones que están en desacuerdo con la moralidad pública, y que exigen, por parte de cada individuo, que tome una postura, bien en concordancia de la Opinión Pública expresada, o bien confirmando que también él se encuentra al margen de esa estructura moral, es decir, del vínculo comunitario. Paul F. Lazarsfold y Robert K. Merton concluirán sobre este particular que «La publicidad colma la laguna entre "actitudes privadas" y "moralidad pública". La publicidad ejerce presión en favor de una moralidad única, y no doble, impidiendo la continua evasión de este problema. Provoca una reafirmación pública y una aplicación — aunque sea esporádicade la norma social» ${ }^{36}$. Estos dos autores proseguirán ilustrando cómo en ocasiones los Mass Media organizan verdaderas «cruzadas» públicas, que ante la presentación de alternativas simples frente a una situación llamativa, que además pondría en juego este vínculo comunitario básico, exigirán una movilización (inquisitorial) en torno a lo que hasta ese momento no era más que un problema difuso e, incluso, indiferente.

A este efecto moralizante de los Mass Media se le suma otro narcotizante, que llevará a tener a amplios sectores de la población políticamente apáticos e inertes. El mecanismo por el cual aparece este sentimiento narcotizante es, primero, por la confusión existente en el espectador entre la

35 La única excepción a este hecho, por sus efectos públicos, sería la organización en redes informales de interacción, a través de las cuales se podrían transferir diferentes valores, actitudes, etc. El ejemplo más llamativo lo tenemos en los Nuevos Movimientos Sociales, que canalizando los valores «postmaterialistas» (Inglehart 1991 y 1992), serían una respuesta precariamente organizada, tal y como requieren tales valores, a un Mundo de la Vida «colonizado» por las racionalidades sistémicas de la organización formal. Sin einbargo, a la hora de darse «publicidad», también necesitan llamar la atención de los Mass Media, utilizando comúnmente para esta invocación la movilización masiva de sus simpatizantes en una gran manifestación «pública».

36 P.F. LAZARSFElK \& R.K. MERTON (1992), p. 241. 
información absorbida pasivamente y la movilización pública en torno un problema, entre el conocimiento de los problemas de actualidad y la acción relacionada con ellos. Se dedica tanto tiempo a leer o escuchar que después queda mucho menos tiempo para la acción organizada; resulta más cómodo asentir en favor de la opinión generalizada. En segundo lugar, la sobreinformación con la que se bombardea a diario al espectador es tan abrumadora que crea en el individuo la sensación de impotencia frente a todos los problemas sociales que le rodean: ¡ bastante tengo con los míos! En tercer lugar, y pese al argumento de la competencia informativa entre los diferentes Mass Media, siempre quedan temas relevantes fuera de toda agenda informativa, como aquellas cuestiones que pudieran poner en la escena pública preguntas vitales sobre la estructura de la sociedad o el status quo. Y por último, un concepto de producción cultural en torno al entretenimiento y la distracción, que aleja la posibilidad de una producción cultural crítica y de calidad ${ }^{37}$. Este sería uno de los temas centrales en el análisis de la cultura en la sociedad de masas, como es la pérdida de nivel cultural en una industria bajo la dictadura de los rendimientos de mercado, es decir, una cultura a la que se le exige que se mantenga a sí misma bajo una lógica de mercado ${ }^{38}$.

En resumen, si la cultura científica había nacido con una clara vocación hacia su aplicación en el trabajo y la acumulación del conocimiento humano a lo largo de la historia, la cultura expresiva queda inscrita en ese otro espacio privado del consumo de ocio, en el que predomina una cultura abierta al entretenimiento y la expresión de valores para la identificación personal, más que la búsqueda de una cualificación en cultura de alto nivel ${ }^{39}$. El vehículo principal de transmisión de patrones culturales generalizados lo acaparan los Mass Media, que en su función mediadora y conformadora del espacio público favorecen la reproducción de las estructuras culturales-morales necesarias para el sostenimiento funcional y legitimación simbólica de los entramados sistémicos. Estos Mass Media operan a un mismo tiempo con las dos lógicas sistémicas clásicas. Por una parte, el «poder», que con el igualitarismo cultural reduce a los individuos a un mero dato estadístico para los índices de audiencia, y siempre en la desventaja del enfrentamiento entre la racionalidad y capacidad de crítica individual y lo que se ha considerado de relevancia pública (verdad consensuada), pues, como afirmó Tocqueville, «El imperio de la moral de la mayoría se funda, en

37 M. Horkheimer y T.W. Adorno (1992), pp. 203-205.

38 D. Bell (1992); MCDonald, D. (1992).

39 Tal y como nos alecciona P. Bourdieu (1991), el consumo de este tipo de cultura no se realiza tanto por un «gusto» natural como por una intención de «distinción» social. 
parte, sobre esta idea: que hay más luces y serenidad en muchos hombres reunidos que en uno solo» ${ }^{40}$. Y por la otra parte, el «dinero», como la lógica de mercado que se impone en una cultura hecha industria, donde ya no se busca la calidad y la creatividad humana, sino un común denominador bajo la forma del entretenimiento lúdico. La única parte del Mundo de la Vida que se mostraría reacia a esta «colonización» de la cultura expresiva por la industria cultural de masas son las redes informales de interacción social, en torno a las cuales se podrían crear identidades sociales, e incluso organizarse eventualmente como movimientos sociales.

\section{Conclusiones}

En primer lugar habría que resaltar el planteamiento del problema de la integración desde una teoría de la acción comunicativa, pues en ella residiría el origen y la condición de posibilidad de la vida social y la existencia misma de la «sociedad». En este sentido, se distinguen dos medios diferenciados a través de los cuales se puede articular la comunicación social, como son la comunicación simbólicamente mediada

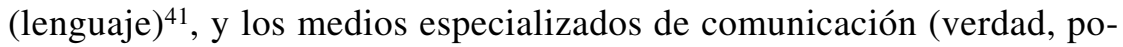
der y dinero). La distinción entre unos y otros como «canales» de comunicación reside en que los primeros hacen referencia a una negociación de sentido entre los participantes en dicha comunicación en condiciones de igualdad posicional y valorativa (esto no niega la existencia de frames situacionales como horizontes de sentido que enmarcan una interacción, sino tan sólo la necesidad de su «actualización», bien sea hacia la reproducción de estructuras o hacia la innovación); por el contrario, los segundos presuponen un código binario en el que

40 A. De Tocqueville (1985), p. 108.

${ }^{41} \mathrm{El}$ arte y otras formas de comunicación simbólica, en el lugar que ocupa la cultura expresiva en la modernidad, también se pueden incluir en este apartado, en cuanto la intención del emisor del mensaje, aunque el «lenguaje» de éste sea pictórico o musical, es la «expresión» de la subjetividad propia a un receptor. No es el mensaje en sí mismo el que se verifica en la experiencia comunicativa, sino la intencionalidad del autor de manifestarse a través del mismo, otorgando en esta trasferencia plástica una pequeña porción de su «alma» a su obra. Por contra, en los canales especializados de comunicación el receptor es «cargado» de información desde la realidad propia del mensaje, donde su emisor, en el mayor de los casos anónimo en la representatividad de su cargo, no interviene presencialmente en la experiencia comunicativa. El mensaje existe «per se», y es en esta «realidad» donde la ciencia, la economía y la política cobran su existencia independiente por mediación de sus códigos de manifestación: la verdad, el dinero y el poder. 
se restringe la comunicación, y que dispensa a los participantes en la misma de la búsqueda de consenso mediante la encarnación de roles diferenciales entre representantes del sistema y su entorno: Poder (funcionario/ciudadano ${ }^{42}$ ), Verdad (experto/lego), Dinero (ofertante «poseedor capital»/demandante «poseedor trabajo»). Lo que diferencia a los portadores de rol en sus relaciones sistémicas respecto a la interacción simbólica en el Mundo de la Vida es un patrón de conducta racionalmente diseñado, que en última instancia remite al código binario por el que se diferencia el sistema de su entorno. Así, un experto en medicina interna, por lo que al código poder se refiere, es tan ciudadano como un peón de la construcción, pues ambos constituyen por igual parte del entorno del sistema político.

La ciencia, como sistema del código verdad, es el más restringido de los sistemas funcionales, pues la comunicación con su entorno, a nivel de roles, es unidireccional ${ }^{43}$.

Al construir el núcleo de generación de conocimiento experto los únicos registros que se contabilizan como inputs para la construcción de la «verdad» son los que se generan en el propio sistema ${ }^{44}$, o los que proceden de los expertos en diáspora por los otros complejos sistémicos, bien sea el político o el económico, o incluso en el retiro de su privaticidad $^{45}$. La otra particularidad del conocimiento experto reside en que sus outputs están dirigidos a los otros sistemas especializados bajo la forma de expertos con la cualificación necesaria para hacerse cargo de su gestión interna. En definitiva, su posición hegemónica en el circuito cibernético de la sociedad funcional consiste en definir los límites

42 También cabe la posibilidad de que el poder se vea autorizado a aplicarse en un nociudadano, como el caso de los inmigrantes, pues su campo de aplicación le otorga competencias funcionales dentro de un territorio geográfico sobre todos los individuos residentes en el mismo (concepto de soberanía).

${ }^{43} \mathrm{El}$ feedback en los otros sistemas se establece bien por participación electoral, bien por organizaciones que representen al factor trabajo en la negociación colectiva con el capital.

${ }^{44}$ Luhmann ratifica nuestro parecer al afirmar: «Los sistemas funcionales, en el transcurso de su proceso de diferenciación, normalmente establecen nuevas asimetrías que sustituyen a las viejas estructuras estratificadas y que se encuentran transversales a éstas; por ejemplo, la asimetría entre producción y consumo en la economía, o la asimetría entre gobernantes y gobernados en el sistema político... Sólo el sistema de la ciencia parece hacer una excepción. No contrapone asimétricamente su propio rendimiento de trabajo a un público que es atendido por él. "El público de los científicos son los científicos"». Luhmann (1996), p. 441.

45 «Todo lo que opere bajo el código verdadero/falso en atención a la ganancia de conocimientos verdaderos o falsos, es ciencia, aunque se dé en el jardín de un convento o en el laboratorio industrial.» Luhmann (1996), p. 449. 
de la «realidad» (oficial), lo posible de lo imposible, lo que pertenece a un sistema y lo que no. Por poner un ejemplo, desde la cultura expresiva del Mundo de la Vida el fenómeno O.V.N.I. es un elemento simbólico que lleva presente al menos medio siglo; sin embargo, hasta que la «autoridad» científica no ratifique su evidencia desde los requerimientos experimentales que le competen, simplemente no existe (al menos para los entramados funcionales), y se convierte en un mito moderno sujeto estrictamente a las creencias particulares. En este ejemplo también se pone de manifiesto cómo el Mundo de la Vida todavía es capaz de generar sus propias interpretaciones de sentido con independencia del conocimiento experto, y, a través de ellas, de gestar una pluralidad de realidades intragrupales, dentro de las cuales el fenómeno O.V.N.I. puede ocupar un primer plano de relevancia en la definición de una de sus «realidades».

Pese a las referencias realizadas en torno a la teoría de sistemas de Luhmann, nuestra orientación estratégica es claramente divergente, pues desde la perspectiva de la integración social no nos interesa el problema de cómo funcionan internamente los sistemas y sus mecanismos de diferenciación, sino los puntos de encuentro o intercambio intersistémico desde la óptica de la ingeniería de sistemas input/output ${ }^{46}$. En este contexto, un punto central en la teoría de sistemas de Luhmann, como es la reducción de complejidad como motor de la diferenciación intrasistémica, deviene en un mero constructo de los mecanismos de conocimiento y reconocimiento de los sistemas expertos, pues sólo el pensamiento «racional», auspiciado por los requerimientos científicos de legitimización (estatus verdad), crea la condición de posibilidad «reflexiva»para

46 El mismo Luhmann admite la posibilidad de esta orientación en el tratamiento de los sistemas, aunque la rechazará por no reflejar la «realidad» autorreferencial de los mismos: «...bajo aspectos de prestación, el sistema entra a un entramado complejo de referencias de input/output. Cada sistema depende de que otros cumplan con su función y esto a un nivel adecuado de desarrollo. Esto sólo es la imagen reflejada de la propia autonomía. Así, la ciencia depende de que el sistema político pueda garantizar la paz, de que se puedan resolver los conflictos jurídicos, de que la economía funcione y de que se realicen los pagos indispensables y de que el sistema educativo forme a la nueva generación... Si se selecciona este aspecto, en forma del modelo input/output, se puede elaborar cómo los sistemas funcionales se enlazan a través de la comunicación; y en forma de escenarios se puede pensar qué sucedería si uno de los sistemas redujera o suspendiera sus prestaciones... Sin embargo, de limitarse uno a un modelo input/output como tal, sería una caricatura del sistema social que destacaría unilateralmente la dependencia e ignoraría por completo la dinámica propia de los sistemas que dependen uno del otro: sería un simple modelo de intercambio. La realidad sólo se descubre si esta descripción input/output se adapta a la descripción de la autopoiesis autorreferencial y operativamente cerrada de los sistemas funcionales», Luhmann (1996), p. 449. 
que el resto de los sistemas funcionales, con sus códigos operativos autorreferenciales, puedan descubrise como tales frente a un entorno. No es ya que el entramado funcional en sistemas operativos se adapte a la progresiva demanda de complejidad social, sino que, más bien por el contrario, el escalonamiento ascendente de complejidad de los sistemas expertos fracciona la realidad en objetos propios de sus especialidades. Incluso más aun, los elementos epistemológicamente construidos por un sistema experto como objetos de conocimiento propio, y como tales reconocidos operativamente, pueden ser reconstituidos en otros sistemas también como elementos propios, de lo que se puede concluir que, aparte del conflicto de competencias, desde la perspectiva de un entorno heterárquico cualquier objeto de la «realidad» (percepción subjetiva) resulta multidimensional para los sistemas de conocimiento (donde cada uno de ellos toma «para sí» la dimensión que le pertenece), de cuya característica polivalente devendría su complejidad intrínseca, así como la de la propia realidad social misma.

Con el modelo cibernético input/output lo que se quiere destacar es que cualquier cambio en cualquiera de las esferas operativas sistémicas va a repercutir, por un efecto de cascada, en el resto de los entramados sistémicos. La paradoja, ya enunciada para el caso de la modernidad, es que, dada la compartimentación disciplinaria de los sistemas expertos, no siempre estos cambios son reconocidos, bajo el filtro operativo de cada sistema, como un elemento de gestión propio, pero que en cambio, por la unidad «natural» del objeto multidimensionado (y más si este objeto es el hombre), los efectos sobre el mismo sí se van a hacer sentir en mayor o menor grado, creando una crisis de validez sobre la reducción de contingencia o complejidad que se pretendía conseguir (acumulación de consecuencias «perversas» o no pretendidas como variables ocultas).

Por último nos quedaría pendiente ensamblar este esquema de vertebración sistémica con una teoría de la motivación apropiada, con la que pudiéramos recuperar el problema de la integración desde la perspectiva de la acción social, es decir, la integración del individuo en la sociedad y sus entramados funcionales. Sin embargo, dadas las limitaciones de espacio en las que, lamentablemente, se circunscribe la extensión de un artículo, poco más se puede hacer que citar, desde un enfoque conductista, la equivalencia del código poder con la sanción negativa y del código dinero con la sanción positiva, incentivos esenciales para buscar el camino legítimo hacia la integración funcional a través de la «iniciación» en las verdades científicas, que a un mismo tiempo, en sus «rituales de paso» de la concesión de títulos oficiales, dispensarían al individuo de una cualificación funcional y un adoctrinamiento en la 
autorresponsabilidad racional. Con ello no haríamos más que empequeñecer un problema que no arranca tanto de las disposiciones funcionales de «inclusión» social, como de las necesidades de autoestima, afecto y reconocimiento personal en el escenario de la integración social (Mundo de la Vida); máxime cuando una función básica para la sociedad (cuando no también una motivación «básica» del aparato instintivo refrendada por el psicoanálisis), como es la reproducción del contingente poblacional, viene a articularse, a través de la institución desinstitucionalizada «familia», en este espacio de la integración social.

\section{Bibliografía}

BeLl, D. (1989), Las contradicciones culturales del capitalismo, Alianza, Madrid.

Bell, D. (1991), El advenimiento de la sociedad post-industrial, Alianza, Madrid.

BeLL, D. (1992), «Modernidad y sociedad de masas: variedad de las experiencias culturales», en Industria cultural y sociedad de masas, Monte Alvira, Caracas.

BERGER P. y T. LuCKMANN (1989), La construcción social de la realidad, Amorrortu, Buenos Aires.

BERIAIN, J. (comp.) (1996a), Las consecuencias perversas de la modernidad, Anthropos, Barcelona.

BERIAIN, J. (1996b), La integración en las sociedades modernas, Anthropos, Barcelona.

BouRdieu, P. (1991), La distinción, Taurus, Madrid.

CASTELls, M. (1995): La ciudad informacional: tecnologías de la información. reestructuración económica y proceso urbano-regional, Alianza, Madrid.

CASTElls, M. (1997), La era de la información. Economía, sociedad y cultura. Vol. 1: La sociedad red., Alianza, Madrid.

DuRKHeIM, E. (1987), Las formas elementales de la vida religiosa, Akal, Madrid.

DuRKheIM, E. (1995), La división del trabajo social, Akal, Madrid.

Eco, U.; F. Colombo, y otros (1995), La nueva edad media, Alianza, Madrid.

GidDens, A. (1994), Modernidad e identidad del yo, Península, Barcelona.

GidDENs, A. (1997), Consecuencias de la modernidad, Alianza, Madrid.

Habermas, J. (1992), Teoría de la acción comunicativa I, Taurus, Madrid.

HABERMAS, J. (1988), Teoría de la acción comunicativa II, Taurus, Madrid.

HORKHEIMER, M. y T.W. ADORNO, «La industria cultural», en Industria cultural y sociedad de masas, Monte Alvira, Caracas, 1992.

Heller, A. (1995), Teoría de las necesidades en Marx, Península, Barcelona.

IBÁÑEZ, J. (1993), «El papel del sujeto en la teoría (hacia una teoría reflexiva)», en LAMO De Espinosa y Rodríguez IbáÑEZ (comp.), Problemas de teoría social contemporánea, Centro de Investigaciones Sociológicas, Madrid.

INGLEHART, R. (1991), El cambio cultural en las sociedades industriales avanzadas, Centro de Investigaciones Sociológicas, Madrid. 
INGLEHART, R. (1992), «Valores, ideología y movilización cognitiva en los nuevos movimientos sociales», en Los nuevos movimientos sociales, Alfons el Magnànim, Valencia.

LAZARSFelK, P.F. y R.K. Merton, (1992) «Los medios de comunicación de masas, el gusto popular y la acción social organizada», en Industria cultural y sociedad de masas, Monte Alvira, Caracas.

LUCKÇAS (1969), Historia y conciencia de clase, Grijalbo, Barcelona.

Luhmann, N. (1995), Poder, Anthropos, Barcelona.

Luhmann, N. (1996), La Ciencia de la Sociedad, Anthropos, México.

MalinowsKi, B. (1981),Una teoría científica de la cultura, Barcelona.

MacDonald, D. (1992), «Masscult y Midcult», en Industria cultural y sociedad de masas, Monte Alvira, Caracas.

MARX, K. (1986), El Capital, Fondo de Cultura Económica, México.

MARX, K. (1989), Manuscritos de Economía y Filosofía, Alianza, Madrid.

Minc, A. (1994), La Nueva Edad Media, Temas de Hoy, Madrid.

PARSONS, T. (1968), La estructura de la acción social, Guadarrama, Madrid.

PARsons, T. (1988), El sistema social, Alianza, Madrid.

SCHUTZ, A. y T. LuCKMANN, (1997), Las estructuras del mundo de la vida, Amorrortu, Buenos Aires.

Tocqueville, A. (1985), La democracia en América, Orbis, Barcelona.

TönNIES, F. (1979), Comunidad y Asociación, Península, Barcelona.

Weber, M. (1993), Economía y Sociedad, Fondo de Cultura Económica, Madrid. WeBer, M. (1995), La ética protestante y el espíritu del protestantismo, Península, Barcelona. 